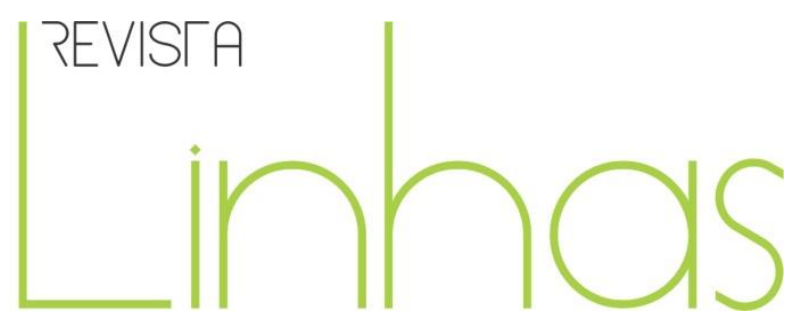

\title{
História da Educação como Arqueologia: cultura material escolar e escolarização ${ }^{1}$
}

\begin{abstract}
Resumo
Nos últimos 20 anos, a comunidade ibero-americana de história da educação tem se preocupado em associar aos documentos textuais outros tipos de fontes de modo a alargar o conhecimento produzido no campo. $O$ expediente tem suscitado o interesse pela preservação e constituição de arquivos e museus escolares. Nessa esteira, a cultura material escolar tem emergido como objeto de investigação e tem sido interrogado na sua dimensão de categoria e fonte para o entendimento da história da escola e do processo de escolarização tanto em Portugal quanto no Brasil. Operar com a materialidade tem trazido um conjunto de desafios teóricos e metodológicos aos pesquisadores do campo e estimulado o diálogo interdisciplinar, em especial com a antropologia e a arqueologia. Nesse sentido, explorar a contribuição desses campos conexos para a escrita da história da educação parece necessário. Para tanto, o artigo está organizado em três partes. Na primeira, procuro identificar a recorrência à cultura material como categoria e fonte na investigação em história. $\mathrm{Na}$ segunda, percurso semelhante é efetuado para a história da educação, tentando realçar as ênfases que têm sido dadas à questão e estabelecendo relação entre cultura material escolar e escolarização. No terceiro momento, as aproximações aos campos da antropologia e da arqueologia se fazem mais presentes visando oferecer subsídios metodológicos para a pesquisa com a materialidade em história da educação.
\end{abstract}

Palavras-chave: Cultura Material Escolar. História da Educação. Escolarização. Agência. Corpo.

\section{Para citar este artigo:}

VIDAL, Diana Gonçalves. História da Educação como Arqueologia: cultura material escolar e escolarização. Revista Linhas. Florianópolis, v. 18, n. 36, p. 251-272, jan./abr. 2017.

\section{DOI: $10.5965 / 1984723818362017251$}

http://dx.doi.org/10.5965/1984723818362017251

\footnotetext{
${ }^{1}$ Este texto serviu de base para a Conferência de Encerramento do XI COLUBHE, realizada na Faculdade de Letras da Universidade do Porto, entre 20 e 23 de junho de 2016 e foi publicado no livro Investigar, Intervir e Preservar em História da Educação, organizado por ALVES, Luís Alberto Marques e PINTASSILGO, Joaquim (Porto: CITCEM, 2017, p. 45-62). Disponível em: <http://web3.letras.up.pt/colubhe/index.php/conferencias/>.
} 


\title{
History of education as archeology: material school culture and schooling
}

\begin{abstract}
In the last 20 years, the Ibero-American History of Education community has made an effort to associate other kinds of sources to the written documents, aiming to enlarge the knowledge produced in this field. The procedure has raised interest in preserving and creating school archives and museums. The material school culture has emerged as an object of research and has been questioned in its dimension of category and source for the understanding of the history of school and schooling process, in Portugal and in Brazil. The work on Materiality has raised theoretical and methodological challenges to the researchers and stimulated the interdisciplinary dialog, particularly with Anthropology and Archeology. Exploring the contribution of these connected fields to the History of education seems therefore necessary. With this purpose, this article is divided into three parts. The first one tries to identify the recourse to material culture, as category and source while researching History. In the second one, a similar path is taken in regard to the History of Education, in an effort to highlight the points which have been receiving emphasis in the research, as well as to establish relations between material school culture and schooling. In the third part, approaches to the fields of anthropology and archeology become more evident with a view to offering methodological support to the research on materiality in the History of education.
\end{abstract}

Keywords: Material School Culture. History of Education. Schooling. Agency. Body. 
Nos últimos 20 anos, a comunidade ibero-americana de história da educação tem se preocupado em associar aos documentos textuais outros tipos de fontes de modo a alargar o conhecimento produzido no campo. O expediente tem suscitado o interesse pela preservação e constituição de arquivos e museus escolares. Nessa esteira, a cultura material escolar tem emergido como objeto de investigação e tem sido interrogada na sua dimensão de categoria e fonte para o entendimento da história da escola e do processo de escolarização tanto em Portugal quanto no Brasil.

Operar com a materialidade tem trazido um conjunto de desafios teóricos e metodológicos aos pesquisadores do campo e estimulado o diálogo interdisciplinar, em especial com a antropologia e arqueologia. Nesse sentido, explorar a contribuição desses campos conexos para a escrita da história da educação parece necessário. Se a antropologia não aparece no título é apenas por estarmos mais habituados a efetuar esta aproximação, o que não ocorre com a arqueologia. Ambas, no entanto, serão escrutinadas neste artigo.

Antes de iniciar, todavia, anuncio duas precauções. A primeira reside no fato de que os estudos sobre a cultura material constituem, eles mesmos, um campo de investigação. Os debates ali instalados podem nos servir de guias na incursão aqui proposta. De acordo com Dan Hicks e Mary Beaudry (2010, p. 5), na introdução de The Oxford Handbook of Material Culture Studies, o campo dos estudos da cultura material desenvolveu-se em duas fases principais. A primeira no segundo quartel do século XIX, particularmente nos museus, como um contraponto à antropologia social de Durkheim. A segunda emergiu como uma forma de associar estruturalismo e semiótica nos anos 1970 e 1980. Este processo pode ser considerado como uma virada da Cultura Material e permitiu uma solução provisória às críticas a uma virada puramente Cultural, reconciliando aparentemente relativismo e realismo, em especial pelo uso das teorias da prática de Giddens e Bourdieu.

Mais recentemente, entretanto, um conjunto de críticas, provenientes do interior dos estudos da cultura material, e argumentos sobre a extensão da agencia humana para os objetos levaram a uma ampliação da ideia de cultura material. Simultaneamente, os estudos do campo têm impactado discussões no âmbito de vários domínios. Associados à arqueologia e à antropologia, despontam ainda aproximações à geografia cultural e à 
ciência e tecnologia. Estas questões irão reaparecer ao nos interrogarmos sobre a presença da cultura material escolar nas investigações em história da educação.

A segunda precaução remete à polissemia do termo. Quando nos referimos à cultura material, tratamos tanto de artefatos, quanto dos elementos materiais do mundo que nos cerca como o meio ambiente, a natureza, o urbanização das cidades, a arquitetura dos edifícios ou mesmo o tempo. Como recurso para permitir melhor circunscrever o debate, proponho-me a discorrer acerca da cultura material e da cultura material escolar a partir de um olhar que recai sobre os artefatos. A estratégia, no entanto, não elide o reconhecimento de que as demais manifestações do mundo material são também significativas quando abordamos a problemática no âmbito da história e da história da educação.

A exposição foi organizada em três momentos. No primeiro, procuro identificar a recorrência à cultura material como categoria e fonte na investigação em história. No segundo, percurso semelhante é efetuado para a história da educação, tentando realçar as ênfases que têm sido dadas à questão e estabelecendo relação entre cultura material escolar e escolarização. No terceiro momento, proponho aproximações aos campos da antropologia e da arqueologia como meio de oferecer subsídios metodológicos para a pesquisa com a materialidade em história da educação.

\section{A cultura material como domínio da história}

Não se pode dizer que incorporar a cultura material como fonte para a história seja uma novidade. Ao contrário, já na década de 1960, Braudel publicou o primeiro dos três volumes de Civilização material e Capitalismo, em que, como um geo-historiador interessado pela cultura, na definição de Peter Burke (1991, p. 61), abordou a civilização com foco nas trocas de bens. Um dos exemplos mais fascinantes, destaca Burke

é o da cadeira, introduzida na China, vinda provavelmente da Europa, no segundo ou terceiro século d.C., sendo amplamente usada por volta do século XIII. Esse novo costume exigiu novos tipos de móveis, mesas altas, por exemplo, e uma nova postura; em resumo, um novo estilo de vida. 
Os japoneses, por outro lado, não aceitaram a cadeira, da mesma maneira que os mouros de Granada (...) (BURKE, 1991, p. 61)

Braudel, no entanto, não era o representante isolado da tendência. Também nos anos 1960, Jean Delumeau lançava o primeiro volume de A civilização do Renascimento, no qual dedicava toda a segunda parte à vida material, com destaque ao progresso técnico, aos negócios, à mobilidade social e às relações entre cidade e campo. A cultura material emergia das mais variadas formas, como artefatos, tais como relógios ou letras de câmbio, ou paisagens e alimentação.

Representavam a mudança operada nos modos de fazer história propostos pela primeira geração dos Annales, em que a ampliação documental se constituía em um dos mais importantes pilares e que ficou consagrada pela citação reiterada deste trecho de Lucien Febvre, publicado originalmente em 1949, no artigo "Vers une autre histoire" (Revue de Métaphysique et de Morale, LVIII):

\begin{abstract}
A história faz-se com documentos escritos, sem dúvida. Quando estes existem. Mas pode fazer-se sem documentos escritos, quando não existem. Com tudo o que a habilidade do historiador lhe permite utilizar para fabricar o seu mel, na falta das flores habituais. Logo, com palavras. Signos. Paisagens e telhas. Com as formas do campo e das ervas daninhas. [...] Numa palavra, com tudo o que, pertencendo ao homem, depende do homem, serve ao homem, exprime o homem, demonstra a presença, a atividade, os gostos e as maneiras de ser do homem. Toda uma parte, e sem dúvida a mais apaixonante do nosso trabalho de historiadores, não consistirá num esforço constante para fazer falar as coisas mudas, para fazê-las dizer o que elas por si próprias não dizem sobre os homens, sobre as sociedades que as produziram, e para constituir, finalmente, entre elas, aquela vasta rede de solidariedade e de entreajuda que supre a ausência do documento escrito? (FEBVRE, 1949 in: LE GOFF, 2003, p. 530)
\end{abstract}

O interesse pela cultura material, entretanto, não se cinge aos Annales. Em 1939, quando saiu a lume o primeiro volume d'O processo civilizador, Norbert Elias já demonstrava atenção aos artefatos na construção de uma interpretação da história dos costumes. Não deixa de ser estimulante acompanhar a argumentação tecida pelo autor sobre os hábitos à mesa, com particular realce para o uso da faca e do garfo. 
Não é meu intuito, aqui, efetuar uma genealogia da presença da cultura material na escrita da história. Apenas desejo marcar que a operação historiográfica no século XX não se podia mais limitar ao uso dos documentos escritos. Era incitada a incluir outras fontes no reconhecimento da materialidade da experiência humana.

No entanto, a introdução dos artefatos como documentos trouxe desafios teóricos e metodológicos ao fazer do historiador. Como narrativa, a história é uma produção escriturária, o que torna mais fácil a incorporação de documentos discursivos (que de não discursivos) ao exercício do historiador. A mera descrição do artefato não resolve o impasse, apenas acentua a discrepância entre as fontes. Nesse sentido, o recurso à interdisciplinaridade despontou como necessário à interpretação histórica, incitando a aproximação, em particular, com a arqueologia e a antropologia.

O deslocamento, no entanto, não foi feito sem problemas. No que concerne à arqueologia, Marcelo Rede (2003, p. 282) sustenta que tem ocorrido uma "transferência um tanto irrefletida dos procedimentos da [disciplina] para o campo da história". Simultaneamente, a história tem demonstrado dificuldade em valer-se da materialidade como fonte, mobilizando documentos escritos "para dar conta da relação entre sociedade e matéria". Rede, entretanto, identifica em um movimento surgido na antropologia na década de 1990, a possibilidade de superação de alguns impasses. Refere-se especificamente ao grupo de trabalho Matière à Penser e, em particular, aos estudos de Jean-Pierre Warnier com foco na análise das práticas sociais pela articulação entre corpo e cultura material.

De fato, aproximar o historiador da cultura material exige também uma atenção às práticas sociais e não somente às ideologias ou às representações. Construir uma teoria das práticas foi um investimento assumido nos anos 1970, por historiadores como Michel Foucault, Michel de Certeau e E.P.Thompson, além de sociólogos, como Pierre Bourdieu e Anthony Giddens, já citados na introdução. Vinha associado a uma decisiva deriva em direção à valorização dos sujeitos e de sua experiência ou agência na sociedade. Suscitou um deslocamento da análise dos artefatos apenas na dimensão de utensílios ou de signos e semióforos. O projeto, no entanto, ainda era reclamado nos anos 1980, quando Certeau publicou A invenção do cotidiano, artes de fazer, e reiterado nos anos 1990 na 
compreensão de que práticas e representações constituem dimensões indissociáveis da vida cultural, como assevera Roger Chartier (1991).

A conciliação entre os ofícios do historiador e do antropólogo, entretanto, implica em concessões mútuas. Se é fato, como assevera Marcel Detienne (2010, p. 20-21), que as duas disciplinas "são igualmente marcadas pela retórica, pelos contextos políticos e sociais como pelo gênero no qual se pensa a análise e a observação", é também reconhecido pelo autor que a historicidade "jamais cativou a curiosidade do saber antropológico". Esta é, aliás, a crítica que encontramos constantemente aos trabalhos que recorrem aos aportes da antropologia em suas análises: uma certa estabilidade conferida aos artefatos no tempo ou uma fraca atenção aos aspectos diacrônicos entre sociedade e cultura material.

Tomados com esta precaução, os aportes de Jean-Pierre Warnier podem oferecer subsídios à interpretação da cultura material. Retomando estudos de Marcel Mauss, base também das reflexões de Bourdieu, Warnier coloca o corpo como balizador maior da experiência material dos sujeitos e se interroga sobre o problema da motricidade. Insiste sobre o fato de que os objetos produzem também "cultura e que a relação que o homem tem com eles participa de sua própria constituição como sujeito individual, social e cultural" (JULIEN;WARNIER, 1999, p. 12). Warnier (1999, p. 139) defende que não há homologia automática entre condutas motrizes e categorias mentais e que a relação com os objetos nas condutas motrizes não é redutível às determinações de classe. Dito de outro modo, "o sujeito, pela prática, faz a síntese entre objeto-corpo e objeto-signo" (WARNIER Apud REDE, 2003, p. 285).

Os pontos centrais de sua proposta podem ser sintetizados em três vertentes: "a rejeição de uma abordagem generalizante, que mascara a particularidade das trajetórias individuais; a defesa da compreensão dos fenômenos sociais a partir de sua materialidade (corporal, objetual) e não apenas sua natureza sígnica; a ênfase na observação de campo" (REDE, 2003, p. 286). O terceiro ponto faz-nos retornar ao problema da incorporação da cultura material como fonte histórica. Para Warnier (1999, p. 140), o estudo se baseia em uma "etnografia das condutas-motrizes-nos-objetos [que] permite fazer uma teoria da relação sujeito-objeto-outro sujeito investida de determinações múltiplas". 
Nesse sentido, talvez não fosse o caso de descartar tão rapidamente os aportes da arqueologia - e o próprio Marcelo Rede (2003) reconhece isto ao mencionar o trabalho de Sophie Beaune, Pour une archeólogie du geste (2000). Operando com um corpus documental constituído por objetos fabricados em um passado longínquo, do qual sabemos pouco, que se situa entre a aparição do Australopithecus e o Neolítico; objetos que foram recolhidos em várias partes do mundo e cujos restos tornam difícil restituir posturas e gestos, Beaune constrói um modelo de análise que busca retraçar não apenas uma utensilagem primitiva, mas os tipos de atividades práticas e mentais, próprias a nossa espécie, assim como alguns traços de evolução perceptíveis através da variabilidade ao longo das eras. Utilizando-se dos estudos traceológicos colocados em relação com usos dominantes que ela atribui aos objetos e sinais de sua manipulação, propõe uma série de esquemas que a conduzem à reconstituição gestual corporal.

Esta discussão parece profícua no que tange à relação entre história e cultura material como fonte e a ela retornaremos mais adiante. Antes, porém, gostaria de explorar os modos como a história da educação tem incorporado a cultura material escolar em suas análises, abordando as interfaces entre materialidade e escolarização.

\section{Cultura material escolar e escolarização}

Juri Meda (2015, p. 9-10) identifica dois possíveis enfoques de cultura material da escola como categoria historiográfica em educação: o primeiro recai sobre a dimensão material do artefato, escrutinando as práticas educativas ocorridas na sala de aula; o segundo se interroga sobre o artefato como um produto industrial e um objeto de consumo, colocando sua natureza pedagógica em segundo plano. A estes dois enfoques ele associa duas tradições historiográficas: uma espanhola, que poderíamos considerar ibero-americana, posto que é também recorrente em Portugal e em países da América Latina (Brasil incluído), de etno-história da escola; outra, italiana, que prefere o termo história material da escola.

Um terceiro enfoque, no entanto, emerge no texto de Martin Lawn e lan Grosvenor (2001). Os autores insistem na compreensão da materialidade a partir de sua relação com a cultura do trabalho. Por certo, esta vertente, aproxima-se do primeiro 
enfoque enunciado por Meda, mas dele se distingue pela ênfase que concede ao artefato como elemento importante na definição da identidade profissional docente. Afirmam os autores que os "professores em seu trabalho partilham suas vidas com objetos"” (LAWN; GROSVENOR, 2001, p. 126).

De fato, no que concerne à produção ibero-americana em histórica da educação, a discussão em torno da cultura material escolar vem associada à concepção de patrimônio histórico-educativo, da intervenção museológica e da reconstrução etnográfica da memória educativa. Isso não implica em dizer que se desconheçam as relações entre materialidade e sociedade industrial ou que se descure de uma análise do habitus do ofício docente. No entanto, o interesse vem mais imediatamente ligado ao registro da cultura empírica das instituições educativas, valorizada, como a ela se refere Agustín Escolano Benito (2010, p 14),

como o expoente visível, e traz sua leitura o efeito interpretado, dos signos e dos significados que exibem os chamados objetos-vestígio (objetos-huella), assim como também as representações que os replicam ou acompanham, fontes intuíveis e manejáveis nas quais ficou materializada a tradição pedagógica ${ }^{3}$.

Ao defender a etno-história da escola, Escolano, no mesmo artigo, destaca seu potencial de decifração do passado a partir de vestígios e das conjecturas formuladas pelo historiador da educação na investigação das marcas ou sinais constitutivos dos objetos, considerados em sua dimensão de semióforos. Ademais, agrega que os artefatos possuem também um poder narrativo, ao "servir de materiais nos quais se apoia a construção de relatos, e por isso justamente se transformam, diferenciada ou conjuntivamente, em textos que, como escritas criadas ou dispostas ao exame, podem ser lidos e interpretados em sua forma e nos conteúdos que se associam" (ESCOLANO BENITO, 2010, p. 18-19). Por fim, ressalta o valor de reservatório patrimonial da memória da cultura material escolar, permitindo uma educação histórica dos sujeitos e dos

\footnotetext{
${ }^{2}$ Tradução livre do original em inglês.

${ }^{3}$ Este e os demais trechos deste artigo foram traduzidos pela autora para o presente estudo. Original em espanhol.
} 
coletivos. Afinal, “educar na memória, no uso crítico da tradição, é sem dúvida uma estratégia básica de sobrevivência, de sustentabilidade cultural, dos indivíduos e da civilização", sustenta o autor (, ESCOLANO BENITO, p. 25).

Esta crença no papel educativo do patrimônio material e imaterial tem dado suporte a iniciativas museológicas, tais como o CEINCE (Centro Internacional de la Cultura Escolar), organizado por Escolano na Espanha. Mas não apenas. Outras ações realizadas no mundo ibero-americano podem ser lembradas, como a defesa do Museu Vivo da Escola Primária, por Margarida Felgueiras, em Portugal; a criação do Museu da Escola, por Anamaria Casassanta Peixoto, ou do Museu da Escola Catarinense, por Vera Gaspar da Silva, ambos no Brasil, e do Museo de la Escuela, por Maria Cristina Linares, na Argentina dentre muitos exemplos. Aqui, ainda, podemos incluir a preocupação com os arquivos escolares por parte de vários pesquisadores, como Maria João Mogarro, Rosa Fatima de Souza, Maria do Carmo Martins, Nádia Gaiofatto Gonçalves, André Paulilo, Maria Cristina Meneses, Carmen Sylvia Vidigal de Moraes, Iomar Barbosa Zaia, dentre vários outros.

O expediente dá visibilidade a um dos principais obstáculos enfrentados para a incorporação da cultura material escolar pelos estudos históricos em educação: a própria localização dos objetos. As mudanças administrativas ou de endereço, as alterações pedagógicas e de finalidades da escola promovem o descarte de tudo ou quase tudo que ficou em desuso ou que foi destruído pela utilização reiterada. A própria política de guarda e descarte das instituições escolares, que preserva os registros das atividadesmeio, sem preservar os testemunhos das atividades-fim, promove o desaparecimento de parte significativa da cultura material escolar.

Parte dessa materialidade, entretanto, é considerada de uso pessoal. São cadernos, pastas, uniformes e outros tantos artefatos que ou repousam no âmbito das famílias, carregados de marcas afetivas, ou foram "jogados fora” com o passar do tempo. Recuperá-los supõe um investimento de pesquisa por vezes demorado e nem sempre bem-sucedido. Relatos de visitas a associações de alunos, de anúncios em rádios e jornais, de busca de nomes e endereços em listas de matrículas, como meios de encontrar sujeitos que ainda detenham objetos escolares em acervos pessoais oferecem indícios dos problemas enfrentados pela investigação histórica em educação. 
Como resposta a estes constrangimentos, pesquisadores em história da educação não só têm se atentado para a criação de museus e arquivos escolares, como mencionado acima, como vêm gerando um intenso debate no campo e, mesmo, produzindo uma extensa bibliografia em que se realça a importância desse patrimônio educativo e a necessidade de políticas específicas para sua preservação.

Estas questões se acentuam à medida que recuamos no tempo, ultrapassando os limites da duração da vida das instituições ou dos sujeitos. Quanto mais remoto o período pesquisado, mais difícil a localização dos artefatos na sua integridade ou a compreensão das práticas que sugeriram ou as formas em que foram apropriados. A impossibilidade de valer-se de depoimentos como fontes no estudo desses artefatos reforça o diálogo disciplinar e a assunção de outras precauções metodológicas. Em geral, a solução vem associada à mobilização de fontes imagéticas e textuais, exercício recorrente do historiador da educação mesmo quando lida com períodos mais recentes. No entanto, a própria materialidade nos escapa na sua dimensão de fonte, o que reitera a crítica exposta anteriormente ao tratar do ofício do historiador.

Valendo-se dos mesmos recursos documentais e na conciliação de uma análise das representações com a interpretação das práticas, situa-se também a proposta de conceber a cultura material escolar como constitutiva da cultura do trabalho docente tal qual emerge no artigo de Lawn e Grosvenor. Os autores não descartam a dimensão econômica no estudo, mas detêm-se em explorar aspectos relativos à sedimentação do trabalho e das culturas do trabalho na escola (LAWN; GROSVENOR, 2001, p. 118). Por um lado, interrogam-se sobre os efeitos de incorporação, por parte da escola, de objetos para escritório fabricados em massa pela indústria. Por outro, destacam a habilidade dos professores em solucionar os problemas surgidos no trabalho por meio de uma produção artesanal de artefatos.

No que concerne ao primeiro tópico, um dos exemplos explorados é o da máquina reprográfica nos anos 1950. A solução encontrada para rotinas administrativas de escritórios passou a ser sugerida para uso escolar em anúncios que destacavam sua economia e eficácia. Ao reproduzir, em boa qualidade e na quantidade necessária, mapas, gráficos, cartas e desenhos, elaborados na escola por canetas e lápis, aumentavam a 
eficiência do trabalho do docente. De simples manuseio, poderiam ainda ser operadas, até, pelos próprios alunos, asseveravam as propagandas.

Lawn e Grosvenor (2001, p. 123-124), entretanto, tencionam as vantagens realçadas pela propaganda. A partir do depoimento de um professor, identificam um conjunto de obstáculos na implementação e uso desses artefatos vendidos comercialmente para a escola, atinentes às imposições do tempo e do espaço escolar, como das relações entre setor administrativo e atividade docente.

No que tange ao segundo aspecto - produção artesanal de artefatos -, os autores afirmam que o professor constrói ferramentas para seu trabalho na medida da tarefa a ser realizada. Ou seja, trabalha mesmo quando não está diante das crianças. Produz a tecnologia utilizada em sala de aula, antes de operá-la. De acordo com Lawn e Grosvenor, esta cultura do trabalho reflete a cultura do "fazer e consertar" ("make do and mend"), característica do ofício artesanal. Reflete também os poucos recursos financeiros de que as escolas dispõem para seu funcionamento.

Como aproximação metodológica para entender o impacto da cultura material na vida laboral de docentes, sugerem a história dos objetos, nos traços indiretos que pode fornecer e no gatilho que oferece para despertar a memória. Sugerem ainda o uso de depoimentos, pois ao discorrer sobre objetos, docentes podem explicar para um outsider a natureza da cultura de seu trabalho, estabelecer vínculos passado e presente da profissão, bem como localizar-se na história. Simultaneamente, a metodologia provê historiadores com fragmentos de experiência, ampliando as informações sobre o trabalho docente, recolhidas em fontes tradicionais (LAWN; GROSVENOR, 2001, p. 126).

Como se pode perceber, os autores remontam, aqui, à aproximação etno-histórica da escola mencionada anteriormente, voltada fundamentalmente, neste caso, à compreensão da atividade e da identidade profissional docente. Diversamente destas vertentes, segundo Meda (2015, p. 11-12), a cultura material escolar pode ser analisada a partir de uma história da indústria escolar, com especial atenção aos processos produtivos e às complexas dinâmicas comerciais vigentes em um mercado suis generis como o da escola entre os séculos XIX e XX. 
Não são poucos os estudos em história da educação que destacam a importância das Exposições Universais e dos Congressos de Instrução a elas associados na disseminação de uma nova cultura material nas escolas no Oitocentos. No Brasil, Moysés Kuhlmann Jr.(1996) já alertava para o fato nos anos de 1990, em seu doutorado As grandes festas didáticas: a educação brasileira e as exposições internacionais (1862-1922). Na literatura internacional, livros sobre a matéria têm sido publicados, dentre eles, especificamente focado na questão está, organizado por Martin Lawn, Modelling the future: exhibitions and the materiality of education (2009), reunindo pesquisadores europeus, latino-americanos e asiáticos.

As Exposições Universais, criadas em 1851, celebravam o progresso da indústria, numa “conjuntura de aceleramento do processo de industrialização, movidas pela estratégia de expansão imperialista do capitalismo" e de metropolização das cidades (BARBUY, 1996, p. 211). Podemos acrescentar, ainda, a proclamação da obrigatoriedade escolar em vários países e a disseminação internacional do método intuitivo e o ensino simultâneo e graduado como princípios de uma escola de massas economicamente viável. A confluência desses fatores gerava o ambiente favorável ao desenvolvimento da indústria escolar.

A categoria indústria escolar implica em outros desafios metodológicos e teóricos. Inicialmente, instiga a ampliar o espectro das fontes, recorrendo à documentação mercantil, como estatutos e balanços corporativos, catálogos comerciais, anuários industriais, notas fiscais, notas de importação, lista de almoxarifado; além de acesso a arquivos privados, o que nem sempre é possível ou existente. Suscita ainda estabelecer diálogo com disciplinas como economia e ciências contábeis, bem como aproximação com a história econômica, da indústria, de empresas, além da história fiscal, dos transportes e das relações diplomáticas e políticas estabelecidas entre os países. Simultaneamente, requer interrogar-nos sobre os efeitos da progressiva padronização dos processos educativos e da intromissão da indústria na produção de demandas escolares, e não apenas de seu atendimento (VIDAL, 2009; VIDAL; SILVA, 2010).

Nesse sentido, defende Meda (2015, p. 23) que a história da escola não pode prescindir 
do estudo dos processos econômicos relacionados com o desenvolvimento da escolarização de massa e a conseguinte transformação da manufatura escolar do século XIX (composta de oficinas artesanais de pequenas dimensões, não necessariamente especializadas, e operativas em uma área extremamente delimitada, frequentemente circunscrita ao âmbito da cidade ou, como muito, da região) naquela indústria escolar que está formada por uma ampla e variada cadeia de produção, composta de médias e grandes empresas industriais, capazes de produzir quantidades significativas de material escolar de todo o tipo a preços mais reduzidos e distribui-los diretamente em todo o território nacional (editoras, tipografias, fábricas de papel, indústria gráfica e cartográfica, fábricas de canetas estereográficas, penas, lápis e lápis de colorir, fábrica de tintas e carpintaria), que encontrava na escola sua saída comercial natural e que constituía um setor em constante expansão no mundo produtivo[...].

Também é importante reconhecer que, em especial no século XIX e primeiras décadas do XX, as empresas voltadas ao mercado escolar, por vezes, tornaram-se fornecedoras dos mais variados objetos da cultura material escolar hegemonizando este tipo de comércio nacional e internacionalmente. Esse foi o caso da Maison Deyrolle. Dentre os objetos que comercializava estavam modelos anatômicos e botânicos, museus escolares, instrumentos científicos, quadros parietais e armários-museus. Na segunda metade do Oitocentos, a Maison alcançara o posto de principal fornecedora do governo francês. Iniciou, então, uma estratégia de expansão de seus negócios, com edição de catálogos em português e espanhol e a contratação de agentes comerciais para atuar como representantes na Europa e América Latina (VIDAL, 2009). A difusão dos produtos Deyrolle nas várias províncias brasileiras no século XIX pode ser apreciada nos artigos constantes do livro Cultura material escolar: a escola e seus artefatos (MA, SP, PR, SC e RS, 1870-1925), organizado por César Castro (2011).

A escola passou a ser consumidora e o professor cliente (MEDA, 2015, p. 21), ao mesmo tempo em que as aquisições passaram a se pautar pelas lógicas de mercado e da legislação que ampara a compra de equipamentos e suprimentos por órgãos públicos. $\mathrm{O}$ mecanismo estimula também o dispêndio das famílias em itens determinados e, raramente, intercambiáveis. Agrega-se, assim, à discussão sobre a indústria escolar uma outra categoria: escola como mercado, com a qual tenho operado em outros textos (VIDAL, 2009; ALCANTARA, 2014), no reconhecimento de que, 
Quanto mais se expande horizontal e verticalmente o sistema, ampliando o acesso e aumentando os anos de escolarização obrigatória, mais a instituição se oferece como um significativo mercado consumidor, sustentado pelo Estado ou pela iniciativa privada que se infiltra num nicho ordenado legalmente pela máquina estatal. A conexão estabelecida desde o século XIX entre inovação pedagógica e inovação material aprofunda-se, criando uma quase identidade entre qualidade de ensino e aquisição de artefatos escolares, particularmente na retórica que domina o campo. (VIDAL; SILVA, 2010, p. 33)

Nesta vertente como nas demais, a materialidade dos objetos escapa do tratamento como fonte. O artefato é tratado como exterior aos sujeitos. Pensar os objetos como constitutivos dos sujeitos escolares, de seus processos de subjetivação e como agente são contribuições trazidas pelos estudos da cultura material. Para tentar enfrentar este desafio, o diálogo com a arqueologia pode ser profícuo. É isto que tentarei explicitar no próximo item.

\section{O historiador da educação como arqueólogo (e antropólogo)}

Se é certo, como afirma Michel de Certeau (1994, p. 92 e seg.), que não se pode deduzir os usos dos objetos, não é possível elidir a percepção de que os objetos têm também uma agência, como assevera Nicole Boivin (2008, p. 129 e seg.).

Defendendo que se deve "analisar o uso por si mesmo", posto que existem formalidades das práticas ou modalidades da ação apoiados em uma arte muito antiga de fazer com, De Certeau (1994, p. 92-95) propõe modelos de análise para o que considera a problemática da enunciação. De acordo com o autor,

Os "contextos de uso", colocando o ato na sua relação com as circunstâncias, remetem aos traços que especificam o ato de falar (ou prática da língua) e são efeitos dele. Dessas características a enunciação fornece um modelo, mas elas vão se encontrar na relação que outras práticas (caminhar, morar etc.) mantêm com sistemas linguísticos. [...]

Esses elementos (realizar, apropriar-se, inserir-se numa rede relacional, situar-se no tempo) fazem da enunciação, e secundariamente do uso, um nó de circunstâncias, uma nodosidade inseparável do "contexto", do qual abstratamente se distingue. Indissociável do instante presente, de circunstâncias particulares e de um fazer (produzir língua e modificar a 
dinâmica da relação), o ato de falar é um uso da língua e uma operação sobre ela. Pode-se tentar aplicar o seu modelo a muitas operações não linguísticas, tomando como hipótese que todos esses usos dependem do consumo. (DE CERTEAU, 1994, p. 96-97, grifos e aspas no original)

De modo a precisar as relações de força que definem as redes em que se inscrevem e delimitam as circunstâncias de que se podem aproveitar, Michel de Certeau propõe passar de uma referência linguística a uma referência polemológica. Com este objetivo, apresenta a distinção entre estratégias e táticas já bastante conhecidas no debate acadêmico lusobrasileiro em história da educação. Vale ressaltar, entretanto, que ao referir-se às táticas como artes do fraco ou artes de fazer, o autor busca abrigo na psicanálise, fundamentalmente ao associar as figuras e metáforas analisadas pela retórica à interpretação que Freud fez sobre o chiste e "as formas assumidas, no campo de uma ordem, pelos retornos do eliminado: economia e condensações verbais, duplos sentidos e contra-sensos, deslocamentos e aliterações, empregos múltiplos do mesmo material etc." (DE CERTEAU, 1994, p. 103, grifos e aspas no original)

Simultaneamente, De Certeau recorre a uma arqueologia multimilenar, quando supõe que as operações táticas respondem

a uma arte imemorial, que não apenas atravessou instituições e ordens sociopolíticas sucessivas, mas remonta bem mais acima que nossas histórias e liga com estranhas solidariedades o que fica aquém das fronteiras da humanidade. Essas práticas apresentam com efeito curiosas analogias, e como imemoriais inteligências, com simulações, os golpes e manobras que certos peixes ou certas plantas executam com prodigiosa virtuosidade. ( DE CERTEAU, 1994, p. 104)

Reconhece, entretanto, que nos tempos atuais, cada vez mais as táticas têm se desancorado das comunidades tradicionais que Ihes circunscreviam o funcionamento e vagado livres em um espaço que se homogeneíza e amplia, tornando os consumidores migrantes.

A reflexão de De Certeau nos conduz a considerar as práticas como usos a partir de relações entre corpo e matéria constituídas historicamente, mas também resíduos de inteligências imemoriais. A arqueologia e a psicanálise se entrelaçam na construção de 
uma teoria da prática, cuja ênfase repousa na capacidade do sujeito subverter o consumo prescrito pela materialidade.

No campo dos estudos da cultura material, no entanto, o debate em torno da agência dos objetos suscita outros desdobramentos à análise. A arqueologia, aqui também, fornece o escopo da argumentação. De acordo com Nicole Boivin (2008, p. 129), os objetos afetam a vida humana. Para a arqueóloga inglesa, a matéria impacta os indivíduos não apenas emocional e sensualmente, como social e biologicamente e até mesmo geneticamente. A agência da matéria, afirma, reside na sua própria materialidade, ou seja, nas suas características físicas. "A relação entre ideia e matéria não tem uma direção única - a matéria como simples meio para a ideia - mas contrariamente envolve um interessante jogo entre as duas" ${ }^{4}$, assevera.

Boivin não pretende se associar à vaga dos estudos que sustentavam o determinismo do mundo material nos anos 1940 e 1950, e que foram criticados nos anos 1970 no âmbito da virada linguística. Ao contrário, reconhece a importância do destaque à construção social e cultural do real permitido pela matriz pós-estruturalista. Sua postura, no entanto, visa conjugar uma preocupação culturalista a um olhar sobre a materialidade que valorize sua interferência sobre os sujeitos. Para a autora,

O que é importante não é apenas a materialidade, mas a ação conjunta da materialidade e do corpo humano engajado em uma atividade particular. As propriedades dos materiais não são nunca objetivas, mas dependem do organismo que as usa. E é aí claro que a cultura emerge, porque mesmo a mais aparente insistente propriedade física pode ser desfeita pelo condicionamento cultural. [...] Mesmo no nível mais básico, materiais e tecnologia não atuam como agentes dissociados da agência humana. Isto não significa que agentes materiais são agentes secundários da agência humana, mas sugere que localizar agência é um exercício complexo que demanda provavelmente novas formas de pensar sobre isso, assim como sobre humanos e coisas. (BOIVIN, 2008, p. 168)

Advoga que o novo materialismo tem permitido um gradual reconhecimento de que a materialidade impõe constrangimentos e abre possibilidades, assim como conduz a

\footnotetext{
${ }^{4}$ As passagens do estudo de Nicole Boivin inseridas neste texto foram traduzidas do original em inglês.
} 
consequências por vezes inesperadas. Esse mundo híbrido de coisas e ideias criadas pelo homem, comenta Boivin, tem mudado nossa própria essência biológica.

As perspectivas de Michel de Certeau e de Nicole Boivin convergem à medida que reiteram a importância de compreender a prática cultural a partir da relação entre o sujeito e a materialidade do mundo que, em ambos os casos, não se restringe aos artefatos, mas engloba o ambiente geográfico, o desenho urbanístico das cidades, as construções arquitetônicas etc. As preocupações de Sophie Beaune, apresentadas na introdução, com a reconstituição do gestual corroboram para complexificar as análises.

As relações entre corpo e cultura material propostas por Jean-Pierre Warnier, combinadas a estes aportes, trazem ainda outras possibilidades de análise, particularmente no que concerne ao conceito de subjetivação, tramado na relação com a motricidade, ou seja, pela percepção de que o corpo também tem, ele mesmo, uma materialidade. O processo de subjetivação, no entendimento de Jean Pierre Warnier (1999), é resultado da síntese corporal.

A síntese corporal (ou esquema corporal) é a percepção sintética e dinâmica que um sujeito tem de si mesmo, de suas condutas motoras e de sua posição no espaço-tempo. Ela mobiliza o conjunto dos sentidos em sua relação com o corpo próprio e a cultura material. Essa síntese é resultado de aprendizagens que continuam e se mantém no curso da existência inteira. Ela demonstra uma grande variabilidade individual, cultural e social, ao mesmo tempo em que garante a continuidade do sujeito em sua relação com o meio ambiente. Ela se dilata e se retrata alternativamente, para integrar objetos múltiplos (automóvel, utensílios domésticos, roupas, equipamentos esportivos etc.) nas condutas motoras do sujeito 5 . (WARNIER, 1999, p. 27)

Para Warnier (1999), mais do que um habitus corporal, decorrente de movimentos repetitivos, no concurso corpo-materialidade, o homem singulariza a sua existência social, constrói a si mesmo como sujeito (REDE, 2003). Em outras palavras, concebe que há técnicas do corpo, ou seja, modos de se servir do próprio corpo enquanto instrumento de ação, padronizados socialmente e aprendidos culturalmente; que se combinam a

\footnotetext{
${ }^{5}$ As passagens do texto de Jean-Pierre Warnier inseridas no presente artigo foram traduzidas pela autora. Original em francês.
} 
técnicas de si responsáveis por uma reinvenção do social, uma variação e diferenciação individual que ocorre com o processo de subjetivação (ALCANTARA; VIDAL, 2017, no prelo).

Desse modo, realizam-se dois movimentos constantes e imbricados. O primeiro remete ao aprendizado e à incorporação de condutas motoras, social e culturalmente produzidas. O segundo implica na heterogeneidade dos sujeitos, de elementos "singularizantes", com a síntese corporal que ocorre "dentro dos limites admitidos pela cultura" (WARNIER, 1999, p. 32). Para o autor, assim, "o corpo nos subjetiva tanto quanto nossos pensamentos" (Idem, p. 33).

Diante do exposto, pode-se afirmar que tomar a cultura material, e para nosso interesse particular a cultura material escolar, como fonte, requer uma atenção às características físicas da materialidade, bem como às suas alterações ao longo do tempo. Requer atentar para os constrangimentos e possibilidades que esta materialidade oferece à vida humana, sem descurar de considerar os efeitos imprevistos. Requer, também, inquirir sobre a interação entre corpo e materialidade, reconhecendo uma formalidade das práticas; por um lado cativa de modalidades de ação ou de uma gestualidade imemorial; por outro, sempre inventiva e sujeita à mudança. Requer, ainda, interrogar-se sobre os modos como ocorrem os processos de subjetivação a partir do corpo tomado na sua materialidade. Requer, por fim, perquirir sobre o que isto nos informa acerca das muitas formas históricas de fazer a educação no espaço escolar e amplia nosso repertório sobre as várias maneiras de viver o processo de escolarização dentro e fora da escola.

\section{Comentários finais}

A fortuna do termo cultura material reside em denotar "que a matéria tem matriz cultural e, inversamente, que a cultura possui uma dimensão material” (Rede, 1996, p. 274). No caso da cultura material escolar, reitera ainda que o processo de escolarização constrói-se no âmbito da cultura, permanentemente na relação que estabelece com os artefatos escolares e a materialidade da escola (seu espaço e tempo). Tomar a cultura material escolar como fonte suscita, assim, ao historiador da educação, interrogar-se acerca dessa tripla tessitura. 
A incursão não é fácil, como pretendi demonstrar. Os obstáculos a serem superados se estendem desde a própria localização de vestígios materiais, do artefato tratado diacronicamente em uma história dos objetos e das sociedades por que passou, até precauções metodológicas atinentes à especificidade da fonte, dos artefatos tratados em sua materialidade no diálogo constante com a arqueologia e da antropologia, de modo a retraçar uma história do corpo e da gestualidade, bem como compreender a agência dos objetos.

Supõe, ainda, investigar os sentidos atribuídos a estes artefatos considerados como semióforos nos tempos pretéritos e atuais, no seio da sociedade e das culturas escolares, a partir de um olhar que se detém nas práticas escolares e no debate pedagógico; ao mesmo tempo em que se interessa pela identidade e atividade profissional docente.

Suscita, também, compreender a lógica industrial e de mercado a que a produção e consumo dos artefatos escolares estão associados, para além da dimensão didática, incitando a uma aproximação com estudos da economia e da indústria, ademais da política e sociologia, cuja frequência é mais constante em nossas pesquisas.

Por certo, são desafios enormes. No entanto, sua superação alarga nosso conhecimento sobre a história da escola e da escolarização e amplia nosso entendimento sobre as tensões existentes no presente na arena educativa. 


\section{Referências}

ALCÂNTARA, Wiara Rosa. Por uma história econômica da escola: a carteira escolar como vetor de relações (São Paulo, 1874-1914). 2014, 339 f. Tese (Doutorado em Educação) Universidade de São Paulo, Faculdade de Educação, São Paulo. 2014.

ALCÂNTARA, Wiara Rosa; VIDAL, Diana. Corpo e matéria: relações (im) previsíveis da cultura material escolar. In: SILVA, Vera Lucia Gaspar da; SOUZA, Gizele de; CASTRO, Cesar. Cultura material escolar em perspectiva histórica: escritas e possibilidades. Vitória/ES, EDUFES (no prelo).

BARBUY, Heloisa. O Brasil vai a Paris em 1889: um lugar na Exposição Universal. Anais do Museu Paulista. São Paulo, v. 4 p. 211-61, jan./dez. 1996.

BEAUNE, Sophie de. Pour une archéologie du geste-Broyer, moudre, piler: des premiers chasseurs aux premiers agriculteurs. Paris: CNRS Éditions, 2000.

BOIVIN, Nicole. Material cultures, material minds: the impact of things on human thought, society, and evolution. Cambridge: Cambridge University Press, 2008.

BURKE, Peter. A escola dos annales (1929-960): a revolução francesa da historiografia. São Paulo: EdUNESP, 1991.

CASTRO, Cesar Augusto de. (Org.). Cultura material escolar: a escola e seus artefatos (MA, SP, PR, SC e RS, 1870-1925). São Luis: Café \& Lapis, 2011.

CHARTIER, Roger. O mundo como representação. Estudos Avançados, v. 5, n. 11, p. 173-191 abril de 1991.

DE CERTEAU, Michel. A invenção do cotidiano: artes de fazer. Petrópolis: Vozes, 1994.

DETIENNE, Marcel. L’identitié nationale, une énigme. Paris: Gallimard, 2010.

ESCOLANO BENITO, Agustín. Patrimonio material de la escuela e historia cultural. Revista Linhas, v. 11, n. 02, p. 13-28, 2010.

HICKS, Dan; BEAUDRY, Mary. The oxford handbook of material culture studies. New York: Oxford University Press, 2010.

JULIEN, Marie-Pierre; WARNIER, Jean-Pierre. Approches de la culture matérielle: corps à corps avec l'objet. Paris: L'Harmattan, 1999.

KUHLMANN JUNIOR, Moysés. As grandes festas didáticas: a educação brasileira e as exposições internacionais (1862-1922). Tese (Doutorado em 1996) - FEUSP, São Paulo, 1996.

LAWN, Martin; GROSVENOR, lan. When in doubt, preserve: exploring the traces of teaching and material culture in English schools. History of Education, v. 30, n. 2, p.117127, 2001.

LAWN, Martin (Ed.) Modelling the future: exhibitions and the materiality of education. Oxford: Symposium Books, 2009. 
LE GOFF, Jacques. História e memória. Campinas, SP: Editora da UNICAMP, 2003.

MEDA, Juri. A história material da escola como fator de desenvolvimento da pesquisa histórico-educativa na Itália. Revista Linhas, v. 16, n. 30, p. 7-28, 2015.

REDE, Marcelo. Histórias a partir das coisas: tendências recentes nos estudos de cultura material. Anais do Museu Paulista. São Paulo. N. Sér. v. 4. p. 265-282, jan. /dez, 1996.

REDE, Marcelo. Estudos de cultura material: uma vertente francesa. Anais do Museu Paulista. São Paulo. N. Sér. v. 8/9. p. 281-291 (2000-2001). Editado em 2003.

VIDAL, Diana Gonçalves. A invenção da modernidade educativa: circulação internacional de modelos pedagógicos, sujeitos e objetos no Oitocentos. In: CURY, Cláudia Engler, MARIANO, Serioja Cordeiro. (Org.). Múltiplas visões: cultura histórica no oitocentos. João Pessoa: Editora Universitária da UFPB, 2009, p. 39-58.

VIDAL, Diana Gonçalves; SILVA, Vera Lucia Gaspar da. Por uma história sensorial da escola e da escolarização. Revista Linhas, v. 11, n. 02, p. 29-45, jul./ dez. 2010.

WARNIER, Jean-Pierre. Construire la culture matérielle: L'homme qui pensait avec ses doigts. Paris: PUF, 1999.

Recebido em: 15/07/2016 Aprovado em: 10/10/2016

Universidade do Estado de Santa Catarina - UDESC Programa de Pós-Graduação em Educação - PPGE Revista Linhas Volume 18 - Número 36 - Ano 2017 revistalinhas@gmail.com 